This article was downloaded by: [Seedat, Mohamed][UNISA University of South Africa]

On: 16 March 2011

Access details: Access Details: [subscription number 780765662]

Publisher Taylor \& Francis

Informa Ltd Registered in England and Wales Registered Number: 1072954 Registered office: Mortimer House, 3741 Mortimer Street, London W1T 3JH, UK

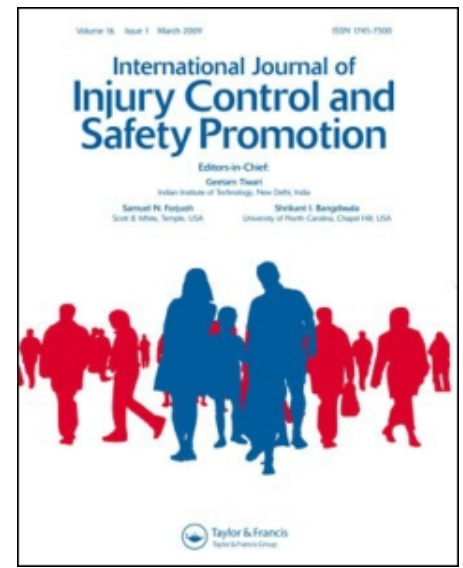

International Journal of Injury Control and Safety Promotion

Publication details, including instructions for authors and subscription information:

http://www.informaworld.com/smpp/title $\sim$ content=t713734346

\title{
Tracing the utility of injury surveillance data in Pretoria (South Africa)
} and Borås (Sweden)

Joanne Gouveia ${ }^{\mathrm{a}}$; Mohamed A. Seedat ${ }^{\mathrm{a}}$; Robert Ekman ${ }^{\mathrm{b}}$; Diana Stark Ekman ${ }^{\mathrm{b}}$; Brett Bowman ${ }^{\mathrm{a}}$

${ }^{\mathrm{a}}$ UNISA Institute for Social and Health Sciences, Lenasia, Johannesburg, South Africa ${ }^{\mathrm{b}}$ Department of

Public Health Sciences, Karolinska Institute, Stockholm, Sweden

First published on: 26 January 2011

To cite this Article Gouveia, Joanne, Seedat, Mohamed A. , Ekman, Robert, Ekman, Diana Stark and Bowman, Brett(2011) 'Tracing the utility of injury surveillance data in Pretoria (South Africa) and Borås (Sweden)', International Journal of Injury Control and Safety Promotion, 18: 1, 75 - 83, First published on: 26 January 2011 (iFirst)

To link to this Article: DOI: 10.1080/17457300.2010.520719

URL: http://dx.doi.org/10.1080/17457300.2010.520719

\section{PLEASE SCROLL DOWN FOR ARTICLE}

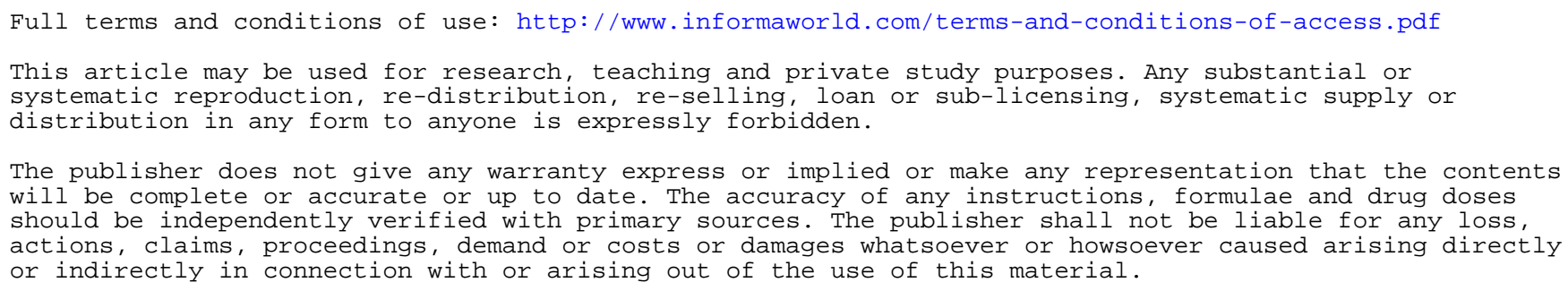




\title{
Tracing the utility of injury surveillance data in Pretoria (South Africa) and Borås (Sweden)
}

\author{
Joanne Gouveia ${ }^{\mathrm{a} *}$, Mohamed A. Seedat ${ }^{\mathrm{a}}$, Robert Ekman ${ }^{\mathrm{b}}$, Diana Stark Ekman ${ }^{\mathrm{b}}$ and Brett Bowman ${ }^{\mathrm{a}}$ \\ ${ }^{a}$ UNISA Institute for Social and Health Sciences, PO Box 1087, Lenasia, Johannesburg, South Africa; ${ }^{b}$ Department of Public \\ Health Sciences, Karolinska Institute, Stockholm, Sweden
}

(Received 25 June 2009; final version received 30 August 2010)

\begin{abstract}
Our research attempted to study the factors that influenced the use of injury data in two cities, representing different injury and socio-economic profiles. In Pretoria, the South African capital city, injury data uptake was constrained by, among other factors, the transitional institutional environment, stakeholders' suspicion of research and the absence of safety promotion champions. In the Swedish city of Borås, injury data uptake was facilitated by wellestablished research agency-municipality partnerships, injury prevention champions, a receptive political and knowledge driven environment and dedicated resources. The study signified the role of a range of content issues, contextual arrangements, social actors who may or may not operate from a perspective of sufficient consensus and institutional communication processes that may either facilitate or hinder the multiple employment and rapid movement of data along the 'ladder of knowledge utilisation'. Safety promotion researchers may need to expand their roles beyond data production to improve data utility.
\end{abstract}

Keywords: injury prevention; data uptake; data utilisation; research utilisation

\section{Introduction}

The value of injury surveillance is primarily determined by the timely production of quality injury data and the rapid uptake and utilisation of that data. Surveillance and other forms of empirically produced data may be deployed for instrumental, conceptual, mobilisation and influence purposes (Nutley, Walter, \& Davies, 2003). The instrumental use of research results in changes in behaviour and practice through a direct link between decisions and empirical data. Conceptual uses inform understandings of a particular situation, but may not lead to changes in policy or practice. Research may be mobilised as a tool of persuasion to justify certain actions, lack of action, or symbolically to validate decisions unrelated to the research data themselves (Lavis, Robertson, Woodside, McLeod, \& Abelson, 2003). Research used to secure wider influence involves attempts to influence policy paradigms and specific belief communities.

Irrespective of the purpose, the uptake of empirical data is influenced by content, contextual, social actor and process factors (Gilson et al., 1999; Hyder, Bloom, Leach, Syed, \& Peters, 2007; Seedat \& Nascimento, 2003; Walt \& Gilson, 1994). Content factors concern the nature, structure and design of proposed interventions and policies. For instance, under certain circumstances data pertaining to communicable diseases may attract greater research utilisation compared to data concerned with violence and social equity. Contextual factors refer to socio-economic and material conditions and the socio-normative values and constitutional commitments of society. Thus, a culture of public engagement in public health debates and politics and the status and influence of the scientific community are important contextual influences (Trostle, Bronfman, \& Langer, 1999; Walt \& Gilson, 1994). Social actor factors are the values, beliefs and vested interests of public health researchers and the receptors' (Hanney, Gonzalez-Block, Buxton, \& Kogan, 2003; Walt \& Gilson, 1994) namely, the decisionmakers. Synergistic interests and the regularity with which researchers and 'receptors' interact are therefore critical for research translation (Hanney et al., 2003). Process factors deal with how research information is communicated and circulated within an organisation and ways in which policy choices are selected and implemented (Gilson et al., 1999; Knott \& Wildavsky, 1980; Walt \& Gilson, 1994) as well as fortuitous opportunities that facilitate research utilisation. While the 'pull' perspective suggests that 'receptor' demands for data is the most significant process factor influencing data utilisation (Landry, Amara, \& Lamari,

\footnotetext{
*Corresponding author. Email: wiggly@global.co.za
} 
2001), the 'push' approach emphasises regular data supply by researchers to 'receptors'. The currency of research is enhanced when data ascend the 'ladder of research utilisation' through a six-stage process (Knott \& Wildavsky, 1980). In transmission, the first stage, empirical results are transmitted from researchers to policy professionals and practitioners as prospective 'receptors'. In cognition, the second stage, the research findings are read and understood by the 'receptors' and in the third stage, the reference stage, the research is regularly cited by decision-makers in documents and discussions with stakeholders. Stage four is defined by efforts to formally adopt the results and stage five is indicated by the influence the research data have on choices and decisions. In stage six, namely, application, the research data are consciously and deliberately applied in policy and practice decisions (Knott \& Wildavsky, 1980).

In brief, a reading of the health and social policy literature reveals that research utilisation is among other factors informed by: the purposes for which empirical evidence is deployed; the socio-political context (Walt \& Gilson, 1994) including the perceived credibility of the researchers and the status of science in society (Gilson et al., 1999; Nutley et al., 2003; Seedat \& Nascimento, 2003); the researcher-end-user relationship; the content of proposed reforms; the processes involved in data uptake, referred to as the 'ladder of research utilisation' (Knott \& Wildavsky, 1980) and the 'demand' and 'push' for data (Landry et al., 2001).

So building on this body of knowledge and other recent studies (see, for example, Albert, Fretheim, \& Maiga, 2007; Brambila, Ottolenghi, Marin, \& Bertrand, 2007; Pablos-Mendez, Chunharas, Langsang, Shademani, \& Tugwell, 2005; Porter \& Hicks, 1995; Seedat \& Nascimento, 2003; Trostle et al., 1999) concerned with factors influencing the utilisation of research findings, in this article we aim to examine the content, contextual, social actor and process factors that influenced the uptake of injury data in Pretoria, South Africa and Borås, Sweden. Our article is motivated by two factors. First, while there is a large body of studies in the broad area of health and social policy (Albert et al., 2007; Brambila et al., 2007; Krug, 1999; Pablos-Mendez et al., 1995; Seedat \& Nascimento, 2003; Trostle et al., 1999; Walt \& Gilson, 1994) concerned with data utilisation, there is a smaller emergent safety promotion body of research focused specifically on the factors influencing the utilisation of injury data. Second, the authors' literature search did not yield studies that trace injury data utilisation across varying socio-economic and injury contexts. In making the comparative analysis, we were mindful that while the city of Pretoria is located within a fairly young democracy, Borås is integral to a longestablished and well-resourced democracy. Our article is the outcome of a South African-Swedish collaborative project centred around the provision of injury epidemiology data, using the available injury surveillance data to stimulate and inform violence and injury prevention initiatives in the two cities which displayed different injury and socio-economic profiles and tracing the factors that influenced data utility.

The second and third authors, as lead members of the collaborative initiative, participated in the conceptualisation of the project and the development of the city-specific injury reports. The first author who had minimum involvement in the distribution of the reports in Pretoria, conducted the interviews and analysis for this article. The fourth author facilitated contact with the key stakeholders in the city of Borås for the interviewing author. As such, the possibility of bias in the analysis was minimised, if not prevented. In the following, we describe the injury reports and distribution strategies and the methods including the profiles of the two cities, data sources and collection and data analysis. Thereafter, we present the results that are discussed in the context of relevant literature in a penultimate section. We conclude with a summary of our main findings and brief implications for safety promotion advocates.

\section{Injury reports}

The Swedish and South African teams used data sources available in their respective countries to produce city-specific reports for the purposes of this study. While the sources differed the reports profiled the injuries and injury priorities for each city, respectively. Following the injury profiles, the Borås report highlighted unintentional injuries among children and the elderly. The Pretoria report placed the accent on violent and traffic fatalities among the 1545-year age group. Both reports also described the respective cities existing injury prevention and safety promotion initiatives and infrastructure. While the reports differed in structure and format they were similar in their focus on injury priorities, rates, responses and infrastructure.

The Borås injury profile was described in several reports including the Child Injury Atlas (birth to 20), the Elderly Injury Atlas (65+) and the Adult Injury Atlas (20-65). These reports were produced by researchers affiliated to a Swedish academic institution. Injury data were derived from three registers: the hospital patient registry, the National Patient Register (The National Board of Health and Welfare, Sweden, 2009) and the National Causes of Death Register (The National Board of Health and Welfare, Sweden, 2009). 
The latter two registers are maintained by the Swedish National Board of Health and Welfare. The hospital patient registry is based on discharge data. All discharges are first coded and collected by the regional health authority and then by the National Board of Health and Welfare in the National Patient Register (The National Board of Health and Welfare, Sweden, 2009). The National Patient Register contains information on: hospitals involved; patient demographics; main diagnosis; secondary diagnoses; external cause of injury; poisoning and surgical procedures. The National Causes of Death Register contains mortality data for all of Sweden (The National Board of Health and Welfare, Sweden, 2009).

The Pretoria injury and prevention reports were developed by researchers at a South African academic institution and their associated partner in the Medical Research Council. The 'Tshwane Non-Natural Mortality Report 2004' detailed the non-natural deaths for a four-year period (2000-2004) and described the geographical, demographic and temporal characteristics of injuries in the city. The 'Current Prevention Initiatives, Responses and Services; Non-Natural Mortality Tshwane Metro 2004' reviewed the city's homicide and traffic prevention strategy and initiatives, identified gaps in its prevention responses and provided recommendations to strengthen the city's injury prevention initiatives.

The Pretoria injury data were obtained from the National Injury Mortality Surveillance System (NIMSS). The NIMSS, a sentinel mortuary-based system, houses information on non-natural deaths that undergo medico-legal investigations in terms of South African law. The NIMSS encapsulates the ICD10 classification system and details information on 22 items including the deceased person's demographics; external cause of injury death; elevated alcohol levels and the temporal and geographical circumstances of the injury deaths. Injury deaths data are collected directly from forensic laboratories. The data are then collated and registered in the NIMSS (Butchart et al., 2001; Donson, 2008; Suffla, Van Niekerk, \& Arendse, 2008).

The injury profiles for Borås and Pretoria varied markedly. Borås, like the rest of Sweden, registers low rates of injuries compared to other centres of the world. In 2005, falls and traffic-related incidents were the most significant external causes of non-natural deaths in the city. Females and those in the $65+$ age category were most at risk for fall-related deaths. Road traffic injury deaths were concentrated among both males and females in the 20-64 years age group followed by those between 0 and 19 . Injury, related to self-directed violence and other directed violence, accounted for a small proportion of injury among males and females (Stark-Ekman, 2007). Overall injury death rates across all age groups, specifically in the 65 + category, declined steadily during a 31-year period (1973-2004) in Borås (Stark-Ekman, 2007). Despite this decline, the elderly and children remained at risk for injury primarily due to falls.

In Pretoria, transport and violence including suicide were the leading causes of injury deaths for both males and females. The deaths were concentrated in the 25-34 years age group and males were disproportionately represented as victims of homicide. Fire-arms were the leading external cause of violent death for the 15-54 age groups. While fire-arm-related homicides dropped from 17.8 per 100,000 in 2000 to 9.6 per 100,000 in 2005 , transport fatalities remained fairly constant at 40.3 per 100,000 in 2000 and 37.4 per 100,000 in 2005 (NIMSS, 2005).

\section{Distribution strategies}

Dissemination of the reports in both cities, were context sensitive and modelled after approaches indicated in the Breakthrough project. As such, the dissemination process attempted to develop and/or strengthen existing networks of interaction between researchers and policy 'receptors' (Hanney et al., 2003; Landry et al., 2001; The Breakthrough Series, 2003), and improve partnerships between 'experts' and health care providers so that both groups can learn from each other, and use findings to improve safety and health for community members in focussed topic areas (The Breakthrough Series, 2003).

In Borås, a dedicated Safety Council is mandated to focus on injury prevention and safety promotion. The Borås Safety Council represents the institutionalisation of the safety mandate and an integrated local infrastructure that involves routine exchanges between the local political leadership, policy-makers, programme implementers and advisors. The Safety Council, embodying regular engagement between different stakeholders, routinely publishes reports on injury data via the city's official website and the media and raises public awareness of safety issues. So in Borås, dissemination of the specific project report occurred with a particular supportive and enabling environment characterised by regular dissemination and use of empirical data and safety focused communications. For the purposes of this study, the lead Swedish researcher forwarded the project report to the Safety Council for dissemination. The Safety Council used its own conferences, face-to-face meetings, small group discussions and telephonic and e-mail contacts and other communication channels to distribute the report. One of the Swedish researchers on this study was also invited to the city's Safety Council to advise 
on interventions including curricula for fall-prevention strategies among the elderly and other emerging priorities. In Pretoria, the safety mandate is located within the Tshwane Metropolitan Police Department (TMPD). The TMPD assumed a strong criminal justice focus and so the project's focus on injuries represented an attempt to stimulate a public health and integrated orientation to safety promotion. At the time of this project, Pretoria was yet to develop a structure dedicated to safety promotion covering all unintentional and intentional injuries. In view of the location of the safety mandate and under-developed safety promotion infrastructure, the Pretoria injury and prevention reports were regularly distributed by members of the study team other than the authors to key social actors who were primarily stationed within the city's police department between 2004 and 2006 . Methods of distribution included interactive workshops, focus groups and one-on-one meetings. In Pretoria, the project team recognising the value of deploying peers in stimulating prevention, also facilitated a breakfast meeting that was sponsored by the Executive Mayor, who is a trained medical doctor. The former Mayor of Bogotá, Colombia, a trained academic, was a keynote speaker at the meeting and so represented an exchange between political peers. The former Mayor presented a case for greater linkages between the city and researchers and illustrated how Pretoria may draw on lessons from Bogotá that utilised empirical data to reduce its injury rates (Guerrero, 2006).

\section{Methods \\ Participant city profiles}

Borås, a member of the international network of Safe Communities, located in Western Sweden, has a population of $99,325,53 \%$ of whom are aged between 25 and 64 years. By the year 2005, approximately $50 \%$ of the residents attained upper secondary schooling (Statistics Sweden, 2005). Commerce, trading and health and social services are leading sources of employment. The average annual income for individuals (20-64 years) is USD $29356^{1}$ (I-Net Bridge, 2008).

Pretoria, the administrative capital of South Africa, is situated in the province of Gauteng and located about $50 \mathrm{~km}$ north of the country's largest city, Johannesburg. The population figures for the year 2005 were 1,986,019 and the sales and services sectors constituted the largest employment sources in the city (City of Tshwane, 2005). The unemployment rate for persons in the 16-65 years age group is $31.5 \%$ and an estimated $58.3 \%$ of the population has no formal income, while $26.9 \%$ of the population fall into the low-income bracket with an annual income of between
156 and 5956 USD annually. The middle-income bracket, constituting $13.4 \%$ of the population, earn between 5956 and 48,150 USD per annum. The highincome group earning above 48,150 USD, comprises only $1.2 \%$ of the population. Less than $50 \%$ of the adult population possess a schooling qualification between grade 8 and grade 12 . At least $16.4 \%$ of the population have no schooling at all.

\section{Data sources and collection}

The selection of interviewees was a carefully considered process. In that informants who were aware of the project and who had specialised knowledge or interest in safety promotion were targeted. Informants also represented the structures and decision-makers responsible for safety in their respective cities. As such, a convenience sample was used to select interviewees representing the TPMD and the Borås Safety Council. Interviewees in Pretoria represented the following divisions of the TMPD: Strategy Development, ByLaw Policing, Road Policing, Crime Prevention, Social Crime Prevention, Reactive and Proactive Policing and Special Operations. In Borås, interviewees included the chief policy developer for the municipality, fire rescue services representatives, the deputy police chief, the director of a woman's shelter and the chief administrator of a drug treatment and rehabilitation clinic. After obtaining informed consent, the lead author, who was not involved in the distribution of reports in Borås and who was minimally involved through the Mayors' meeting in Pretoria, conducted all the interviews in English both in Pretoria (April-June 2007) and Borås (May 2007). All in all, the lead author conducted 10 interviews in Borås and 14 in Pretoria. A semi-structured interview schedule, consisting of 32 questions, focused on content, context, social actor and process issues, served as the information gathering tool. It was developed by the two principal South African Researchers and piloted in Pretoria. The semistructured interview schedule facilitated consistency in data collection in both Borås and Pretoria.

The first two authors also reviewed documents, such as the Tshwane Crime Prevention Strategy, Tshwane Safer City Policy and the Boräs Annual Reports of the Safety Services to obtain background information about the two cities injury prevention policies and interventions. For the purposes of our study, the interviews provided the data to trace the utility of empirically produced reports in the two cities.

\section{Data analysis}

All the interviews were transcribed and typed up by the first author using a computer word processor. A 
thematic content analysis was conducted on these data following the interpretive methods described by Braun and Clarke (2006), Terre Blanche and Durrheim (1999) and Ulin, Robinson, Tolley and McNeill (2002). Thematic content analysis is 'a method for identifying, analysing and reporting patterns (themes) within data' (Braun \& Clarke, 2006, p. 79). In accordance with the interpretive thematic content approach, the first author was able to gain insight into the contextual, social actor, content and process factors that influenced data uptake in the two cities. The actual process of thematic content analysis included four steps. In step 1, the first author read the transcribed materials in order to familiarise herself with the content and delineate and identify emergent themes. In step 2, she re-read the interview materials closely for common themes and coded the themes as they pertained to the four factors: context, social actor, content and process factors. In step 3, using the word processor cut and paste function, she organised and assembled the coded material under the four thematic headings, and determined similarities and differences across the two cities. Since researchers play a cardinal role in defining issues, interpreting information and guiding the research process in qualitative studies (Ulin et al., 2002), in step 4 the analysing author adopted measures to ensure that data were analysed consistently and according to the norms and requirements of qualitative methodology. So, randomly selected interview data were independently coded and analysed by project team members other than the authors. In the few instances where differences occurred when assigning specific themes and categories, consensus was reached through discussion between the analysing author and the project team members who served as independent analysts. This step allowed independent analysts to comment on the categorisation and theme identification process and authenticity, thereby curtailing possible bias in the analysis. Since the analysing author was not involved in the distribution of reports in Borås and minimally involved by way of participation in the Mayors meeting in Pretoria, we were able to ensure sufficient independence in the data analytical process. Content analysis allowed the authors to create a detailed thematic record of the issues arising from the interviews under the four analytic factors: content, context, social actor and process. These are detailed below.

\section{Results}

\section{Content factors}

The Pretoria respondents commended the reports for informing and widening the recipients' understanding of prevention practices as exemplified by a member of the Crime Prevention Unit who said, 'This (report) is what every police officer needs to know in order to help the community ... it makes me aware of what is available in terms of prevention'. Several respondents requested regular updates on best practices for prevention and quick reads in the form of summary boxes, best articulated by an interviewee who suggested '... that most people rather want to be informed by listening than reading a complicated report'. Respondents requested user-friendly reports which could be read quickly in the context of capacity and time constraints.

The Borås reports were used to adopt public health-oriented conceptions of injury prevention, define reduction targets and mobilise public support for helmet campaigns. Respondents also suggested that the city employed the reports instrumentally, namely to prioritise the safety of the elderly and young children and identify sports-related injuries as an emerging priority. The instrumental utilisation of injury data was succinctly explained by a policy analyst: 'results are very important... our work is built around figures... everyone knows that injury prevention(s) saves money and lives'.

\section{Contextual factors}

Four contextual issues limited the injury data to conceptual and reference uses in Pretoria: organisational transformation, fiscal constraints, the definition and location of injury prevention and ambivalence towards science. After the demarcation of new municipal boundaries and the establishment of Pretoria as a mega-city in 2000, the city experienced changes in its organisational and governance structures, policy mechanisms and financial protocols, which in turn introduced a great deal of flux in the executive leadership, decision-making structures and overall strategic planning processes. Within a climate of fluidity and limited budgets, priorities were reconsidered and projects tended to be placed on hold. In fact, competing priorities tended to create a shift towards investing in areas defined as critical. At the time, injury prevention was not defined as a priority and was conflated with crime prevention through its location within the TMPD, who privileged a criminal justice approach to safety promotion. Although respondents valued the reports for their conceptual insights, the TMPD required city officials to function according to criminal justice-oriented strategic plans. One interviewee said 'We operate according to the Metro Police mission and vision rules laid out for us. The reasons are not always explained'. Likewise, the researchers were unable to facilitate significant support for public health focused injury prevention among the 
most senior decision-makers. One Special Operations interviewee explained 'decisions ... like about budgets and major strategy is taken at the highest level ... the Mayoral Committee votes and then decisions go to the Council for approval'.

The Pretoria reports tended to be circulated among mid-level managers and city officials some of whom may have regarded academics and their interventions with a degree of ambivalence. An email request for additional information sent by one of the co-authors to a city employee elicited the following response: 'yet another request [for information]' and 'we have had cases in the past where the Municipality was approached by persons doing research for academic purposes'. Even though the particular city employee was repeatedly exposed to the injury reports and their logic, the reading of our request as 'academic' does raise questions about how science and empirically based interventions may be regarded by officials in the city's administration.

In contrast, in Borås the multiple uses of injury data were enabled by a stable city level political administration that invested economic and institutional resources towards empirically informed injury prevention initiatives. Respondents revealed that a politically supported Safety Council located within the public administration facilitated effective injury prevention policy development and implementation. Consistent with Sweden's enlightenment approach to science, the Safety Council relied heavily on empirical research and internationally bench-marked knowledge products - produced and/or disseminated academic institutions and other agencies - to inform programmatic and budgetary decisions and evaluate interventions. In a reference to empirical research, the deputy fire chief explained, '... we use the "big picture" to make priority decisions ... and there is no classified information ...'?

\section{Social actor factors}

Although the Pretoria respondents expressed conceptual receptivity for the reports, there were no identifiable champions who worked to drive the mission of injury prevention in the city. Within the fluid environment respondents felt under-capacitated, expressed a sense of uncertainty about their future and tended to view championship as the responsibility of senior political leadership and the executive mayor in particular.

In Borås, guided by a common agenda and a desire to 'make a difference' in their jobs, members of the Safety Council and municipal officials supported by enabling institutions served as active champions for safety promotion. The municipal affiliated social actors appreciated the value of science, had the requisite capacity to read empirically produced reports and actively solicited data for specific purposes. Likewise, the Swedish researchers also transmitted empirical reports at crucial times within the city's strategic planning cycles so as to ensure that injury prevention remained a key area of focus. Among those who displayed high levels of commitment and enthusiasm, the chairperson of the traffic Safety Council and the co-ordinator of policy development for the municipality acted to facilitate and maintain mutually supportive relationships between the municipality and researchers affiliated with academic institutions. These social actors developed systems to maintain continuity through institutional changes. For instance, before her retirement the senior policy development co-ordinator introduced the next incumbent to the network of researchers, processes of decision making and the sources of research.

\section{Process factors}

In Pretoria the primary recipients of the reports, who operated at mid-management level, circulated the reports within their own departments. For instance, the acting director of the Social Crime Prevention Unit and the director of the Special Operations Unit within the Social Crime Prevention Unit circulated the reports within their respective departments to encourage the continuation of existing projects. So in Pretoria the injury reports did not ascend up the ladder of research utilisation towards deployment in strategic policy actions. The lack of regular and consistent communication between the South African co-ordinators of the project and Pretoria mid and senior-level leadership also hindered the uptake of injury data.

While we were unable to trace any direct outcomes arising from the former Bogota Mayor's inputs, 12 months after completion of this study the University's senior management approached the researchers with a specific brief. The researchers were requested to act as the preferred injury prevention research service provider for the city of Pretoria. The request arose in the context of a memorandum of understanding (MOU) negotiated between the city and the university, independent of our study. Nonetheless, the MOU may be read as indicative of Pretoria's willingness to consider academic participation in prevention policy and programming and may augur well for strengthening science-policy linkages.

The Borås interviews suggest that those entrusted with safety promotion used institutional structures and organisational communication channels to apply empirical data in policy and programming decisions. Safety champions, who knew where and how to obtain 
research, employed entrenched city administrative structures to request specific data from research agencies when necessary and convene regular meetings at which participants shared information, discussed new research findings and reviewed evidence-based safety promotion strategies. Likewise, the Swedishbased researchers frequently distributed epidemiological data on fatal and non-fatal injuries to maintain the 'push' on the Borås municipality to recognise emerging injury priorities and the outcome of safety initiatives, thereby supporting institutional processes facilitative of research translation.

\section{Discussion}

Our study, a city-based comparative examination of injury data translation, permits us to register two key observations. First, research translation, integral to intricate city level decision-making mechanisms, is mediated by a range of inter-related content, contextual, social actor and process factors (Walt \& Gilson, 1994). Second, when these interactive factors operate advantageously they enable empirical data to be used for instrumental, conceptual, mobilisation and influence purposes (Nutley et al., 2003) and encourage routine movement of empirical data from transmission through to application as conceptualised by Knott and Wildavsky's (1980) six-stage process model.

Borås demonstrated several critical elements in research translation where the use of empirical reports was facilitated by a well-resourced and smoothly functioning city authority that appreciated science and an institutionalised culture of injury prevention. The employment of data was in itself reflective of a long and established national democratic tradition which valued knowledge-driven solutions. The Swedish researchers witnessed rapid movement from cognition to application (Landry et al., 2001), when research into the prevalence and causes of head injury was utilised in a Borås municipality effort to prevent head injuries. The effort led to reductions in injury treatment medical costs.

In Borås, the interactive longstanding relationship between the academic institution and the municipality, the conducive institutional arrangements, and the actions of a critical mass of champions coalesced to support the long and well established process of moving reports from 'transmission' to 'application' (Knott \& Wildavsky, 1980). In contrast, the city of Pretoria epitomised challenges to data uptake in a highly fluid context marked by scarce resources, redress demands linked to the legacy of apartheid and a transforming organisational culture. The Pretoria reports primarily fulfilled conceptual purposes, in that respondents valued their accessibility and suggestions for improving violence and traffic injury prevention initiatives (see Lavis et al., 2003; Nutley et al., 2003). In Pretoria, where the researchers had assumed a 'push' approach independent of the city's strategic planning processes, the empirical reports tended to be used just for cognitive and reference purposes (Knott \& Wildavsky, 1980; Landry et al., 2001). The limited use of empirical reports was indicative of potential social actors' tendencies to relinquish championship to executive decision-makers. However, we caution against reading Pretoria as an African country illustration of endemic contextual resistance to data translation. Instead it is to be viewed as an example of a constellation of factors that hinders data uptake during a particular period in a specific city's transformation trajectory. A recent South African study provides a successful example of how empirical data and information from systemic reviews informed maternal health care policy and clinical guidelines for the treatment of pre-eclampsia and eclampsia (Daniels \& Lewin, 2008). The study, echoing our findings, showed that data uptake relies on interdependent factors: a supportive institutional context, receptivity to academic participation in policy-making, research networks that promote evidence-based planning and serendipitous windows of opportunity which allow researchers to bring relevant data to the attention of policy-makers at the 'right time' (Daniels \& Lewin, 2008).

Following such observations and other findings (Choi et al., 2005; Daniels \& Lewin, 2008; Mitton, Macnab, Smith, \& Foster, 2008), our study confirms that empirically produced reports are rendered facilitative when they are packaged in accessible, meaningful and action-oriented forms, consider the endusers' needs, provide evidence-based criteria for policy or programme implementation, and take cognisance of users' capacities to read technical presentations. Most importantly, empirical reports are useful when they serve to support researcher-end-user relationships within networks of information sharing. Echoing Mexican and South African studies, (Seedat \& Nascimento, 2003; Trostle et al., 1999) our analysis reiterates that a stable and enabling political environment, which includes networks of researchers, decision-makers and community representatives, is central to research translation. Whatever the differences in injury profiles across geographical sites, empirically produced data may find significant resonance in policyand service-oriented initiatives when contexts are distinguished by stability, well-managed organisational transitions and a leadership that appreciates science. Furthermore, research-translation contextual opportunities seem to be rendered meaningful when social actors proceed with sufficient consensus among themselves to actively champion a specific issue.

Consistent with other research (Hanney et al., 2003) signifying the importance of social actors, our study 
showed that data translation is facilitated in favourable contexts wherein there is common understanding among various social actors about the utility of science, mutually beneficial and regular networked exchanges between data producers and users and sufficient processes aligning the parties' strategic orientations. Like several other studies (Hyder et al., 2007; Mitton et al., 2008; Seedat \& Nascimento, 2003; Trostle et al., 1999) that point to the public as constituting important groups of social actors, the Borås work revealed how public support for the introduction of bicycle helmets for those under the age of 14 years facilitated the research translation process towards the application phase. In this sense, in Borås the data utilisation process itself was characterised by both 'pull' and 'push' features (Landry et al., 2001).

\section{Conclusion}

Echoing other findings (Hyder et al., 2007; Mitton et al., 2008; Seedat \& Nascimento, 2003; Trostle et al., 1999; Walt \& Gilson, 1994), our study showed that successful research translation is contingent on favourable content, contextual, social actor and process influences. When these influences interact optimally, research may enjoy significant application in practice and policy decisions and research may be deployed for multiple purposes, including community mobilisation and informing policy implementation. In Borås, a high-income city wherein safety promotion was institutionalised through appropriate infrastructural arrangements, an accent on empirically driven policies, regular interactive exchanges between a multi-sectoral group of stakeholders, active championship by both researchers and policy-makers data enjoyed currency at multiple levels. In this respect Borås, exemplified Knott and Wildavsky's model of research utilisation in that empirical data, including reports produced by the study reported in this article, were routinely transmitted and utilised to frame public health-oriented safety promotion policies and interventions. In contrast in Pretoria, marked by transitional institutional arrangements, a policy flux, competition for scarce resources, an inordinate focus on criminal justice measures, an absence of active championship and safety promotion infrastructure, empirical produced injury data found limited currency. The injury reports were used in a limited way for reference purposes primarily among mid-level managers.

Our findings, following the method of thematic content analysis and the deployment of independent analysts to check on the accuracy of thematic identification and categorisation support the body of theories and research in health policy and safety promotion. Our study emphasises the particular criticality of both context and social actors in low- to middle-income situations, such as South Africa (Seedat \& Nascimento, 2003) and Mexico (Pablos-Mendez et al., 2005) as well as in high-income countries (Albert et al., 2007; Hanney et al., 2003; Hyder et al., 2007).

Our findings suggest that injury prevention researchers would need to expand their traditional research roles so as to exercise academic citizenship innovatively and re-think the process of knowledge production, dissemination and application. Research translation ought to be approached as a planned and systematic process. In this respect, safety promotion researchers and advocates may systematically enhance the utility of injury surveillance and other empirically produced data by: facilitating enabling contexts, packaging reports in ways that speak to end-user needs, identifying institutional champions and promoting routine inter-sectorial communication.

\section{Note}

1. For comparative purposes, both Swedish Kroner (SEK) and South African Rand (ZAR) have been converted to United States Dollars (USD) using the average exchange rate for each currency for the period 2005 .

\section{References}

Albert, M., Fretheim, A., \& Maiga, D. (2007). Factors influencing the utilization of research findings by healthpolicy makers in a developing country: The selection of Mali's essential medicines. Health Research Policy and Systems, 5. Retrieved February 20, 2008, from http:// www.health-policy-systems.com/content $/ 5 / 1 / 2$

Brambila, C., Ottolenghi, E., Marin, C., \& Bertrand, J.T. (2007). Getting results used: Evidence from reproductive health programmatic research in Guatemala. Health Policy and Planning, 22, 234-245.

Braun, V., \& Clarke, V. (2006). Using thematic analysis in psychology. Qualitative Research in Psychology, 3, 77101. Retrieved July 20, 2007, from http://0-proquest. umi.com.innopac. wits.ac.za/pqdweb?index $=4 \&$ did $=1035$ $306391 \&$ SrchMode $=3 \&$ sid $=2 \&$ Fmt $=6 \&$ VInst $=$ PROD $\&$ VType $=\mathrm{PQD} \& \mathrm{RQT}=309 \& \mathrm{VName}=\mathrm{PQD} \& \mathrm{TS}=1195736$ $508 \&$ client $\mathrm{Id}=57035 \&$ aid $=1$

Butchart, A., Peden, M., Matzopoulos, R., Phillips, R., Burrows, S., Bhagwandin, N., ... Cooper, G. (2001). The South African National Non-natural Mortality Surveillance System - Rationale, pilot results and evaluation. South African Medical Journal, 91, 408-417.

Choi, B., Pang, T., Lin, V., Puska, P., Sherman, G., Goddard, M.,... Clottey, C. (2005). Can scientists and policy makers work together? Journal of Epidemiology and Community Health, 59, 632-637.

City of Tshwane (2005). Third Revised Tshwane IDP 2005/6. City of Tshwane. Retrieved March 21, 2007, from http:// www.tshwane.gov.za/idp2005.cfm

Daniels, K., \& Lewin, S. (2008). The practice policy group. Translating research into maternal health care policy: A qualitative case study of the use of evidence in policies for the treatment of eclampsia and pre-eclampsia in South Africa. Health Research Policy and Systems, 6, 12. Retrieved February 16, 2009, from http://www.healthpolicy-systems.com/content/pdf/1478-4505-6-12.pdf 
Donson, H. (Ed.). (2008). A profile of fatal injuries in South Africa 2007. Tygerberg: MRC-UNISA Crime Violence \& Injury Lead Programme.

Gilson, L., Doherty, J., Mcintyre, D., Thomas, S., Brijlal, V., Bowa, C., \& Mbatsha, S. (1999). The dynamics of policy change: Health financing in South Africa, 1994-1999. Johannesburg: Centre for Health Policy and Health Economics Unit.

Guerrero, R. (2006). Violence prevention through multisectoral partnerships: The cases of Cali and Bogata, Columbia. African Safety Promotion: A Journal of Injury and Violence Prevention, 4, 88-98.

Hanney, S., Gonzalez-Block, M., Buxton, M., \& Kogan, M. (2003). The utilization of health research in policymaking: Concepts, examples and methods of assessment. Health Research Policy and Systems, 1. Retrieved February 20, 2008, from http://www.health-policy-sys tems.com/content $/ 1 / 1 / 2$

Hyder, A., Bloom, G., Leach, M., Syed, S.B., \& Peters, D.H. (2007). Future health systems: Innovations for equity, 2007. Exploring health systems research and its influence on policy processes in low-income countries. BMC Public Health, 7, 1-12.

I-Net Bridge. MoneyMate. Retrieved November 19, 2008, from http://www.inet.co.za

Knott, J., \& Wildavsky, A. (1980). If dissemination is the solution, what is the problem? Knowledge: Creation, Diffusion, Utilization, 1, 537-578.

Krug, E. (Ed.). (1999). Injury: A leading cause of the global burden of disease. Geneva: World Health Organisation (WHO).

Landry, R., Amara, N., \& Lamari, M. (2001). Climbing the ladder of research utilization. Science Communication, $22,396-422$.

Lavis, J., Robertson, D., Woodside, J.M., McLeod, C.B., \& Abelson, J. (2003). How can research organizations more effectively transfer research knowledge to decision makers? The Milbank Quarterly, 81, 221-248.

Mitton, C., Macnab, Y., Smith, N., \& Foster, L. (2008). Transferring injury data to decision makers in British Columbia. International Journal of Injury Control and Safety Promotion, 15, 41-43.

National Injury Mortality Surveillance System (NIMSS) (2005). A profile of fatal injuries in South Africa. Paper presented at the 7th Annual Report of the National Injury Mortality Surveillance System, Section 5 Tshwane/Pretoria Metropolitan AreaTygerberg: Medical Research Council/UNISA Crime, Violence and Injury Lead Programme.

Nutley, S., Walter, I., \& Davies, H. (2003). From knowing to doing: A framework for understanding the evidence into practice agenda. Evaluation, 9, 125-148.

Pablos-Mendez, A., Chunharas, S., Langsang, M., Shademani, R., \& Tugwell, P. (2005). Knowledge translation in global health. Bulletin of the World Health Organization, 83. Retrieved February 20, 2008, from http://www. who.int/bulletin/volumes/83/10/editorial21005html/en/ print.html
Porter, R.W., \& Hicks, I. (1995). Knowledge utilization and the process of policy formulation: Toward a framework for Africa. Washington, DC: United States Agency for International Development.

Seedat, M., \& Nascimento, A. (2003). The use of public health research in stimulating violence and injury prevention practices and policies: Reflections from South Africa. Journal of Prevention and Intervention in the Community, 25, 31-47.

Stark-Ekman, D. (2007). Injury surveillance data utility and impact: Developing the injury data prevention, and practice nexus 2003-2007. Final Report, KI Report 3. Stockholm, Sweden: Division of Social Medicine, Department of Public Health Sciences, Karolinska Institute.

Statistiska Centralbyran (SCB) Statistics Sweden (2005). Retrieved February 29, 2008, from http://www.scb.se/ default_2154.aspx

Suffla, S., Van Niekerk, A., \& Arendse, N. (2008). Female homicidal strangulation in urban South Africa. $B M C$ Public Health, 8. doi:10.1186/1471-2458-8-363.

Terre Blanche, M., \& Durrheim, K. (1999). Research in practice: Applied methods for social sciences. Cape Town: University of Cape Town Press.

The Breakthrough Series: IHIs Collaborative Model for Achieving Breakthrough Improvement (2003). IHI Innovation Series white paper. Boston, MA: Institute for Healthcare Improvement. Retrieved August 30, 2010 from http://www.ihi.org/IHI/Topics/Improvement/ SpreadingChanges/Literature/TheBreakthroughSeriesI HIsCollaborativeModelforAchieving+BreakthroughIm provement.htm

The National Cause of Death Register. The National Board of Health and Welfare. Sweden. Retrieved March 16, 2009, from http://www.socialstyrelsen.se/en/Statistics/ statsbysubject/The_Cause_of_Death_Register.htmm

The National Patient Register. The National Board of Health and Welfare. Sweden. Retrieved March 16, 2009, from http://www.socialstyrelsen.se/en/Statistics/statsbysubject/ The + Swedish + Hospital+Discharge + Register.htm

Trostle, J., Bronfman, M., \& Langer, A. (1999). How do researchers influence decision-makers? Case studies of Mexican policies. Health Policy and Planning, 14, 103114.

Ulin, P.R., Robinson, E.T., Tolley, E.E., \& McNeill, E.T. (Eds.) (2002). Qualitative methods: A field guide for applied research in sexual and reproductive health. Research Triangle Park, North Carolina: Family Health International.

Walt, G., \& Gilson, L. (1994). Reforming the health sector in developing countries: The central role of policy analysis. Health Policy and Planning, 9, 353-370. 